\title{
70-year old female patient with mismatch between hematocrit and hemoglobin values: the effects of cold agglutinin on complete blood count
}

\author{
Şerif Ercan*1, Mustafa Çalışkan², Erhan Koptur ${ }^{3}$ \\ 'Department of Clinical Biochemistry, Lüleburgaz State Hospital, Kırklareli, Turkey \\ 2Departments of Clinical Microbiology, Lüleburgaz State Hospital, Kırklareli, Turkey \\ ${ }^{3}$ Home Health Services, Lüleburgaz State Hospital, Kırklareli, Turkey \\ *Corresponding author: serifercan@yahoo.com.tr
}

\begin{abstract}
Introduction: There are a number of pre-analytical and analytical factors, which cause false results in the complete blood count. The present case identifies cold agglutinins as the cause for the mismatch between hematocrit and hemoglobin values.

Materials and methods: 70 -year old female patient had a history of cerebrovascular diseases and rheumatoid arthritis. During routine laboratory examination, the patient had normal leukocyte and platelet counts; however, the hemoglobin (Hb: $105 \mathrm{~g} / \mathrm{L}$ ) and hematocrit (HCT: $0.214 \mathrm{~L} / \mathrm{L}$ ) results were discordant. Hemolysis, lipemia and cold agglutinin were evaluated as possible reasons for the mismatch between hematocrit and hemoglobin values.

Results: First blood sample was slightly hemolysed. Redrawn sample without hemolysis or lipemia was analyzed but the mismatch became even more distinct ( $\mathrm{Hb}: 104 \mathrm{~g} / \mathrm{L}$ and $\mathrm{HCT}: 0.08 \mathrm{~L} / \mathrm{L})$. In this sample, the titration of the cold agglutinin was determined and found to be positive at 1:64 dilution ratios. After an incubation of the sample at $37^{\circ} \mathrm{C}$ for 2 hours, reversibility of agglutination was observed.

Conclusion: We conclude that cold agglutinins may interfere with the analysis of erythrocyte and erythrocyte-related parameters (HCT, MCV, MCH and $\mathrm{MCHC}$ ); however, Hb, leukocyte and platelet counts are not affected.
\end{abstract}

Key words: complete blood count; cold agglutinin; hematocrit; hemoglobin; interference

\section{Introduction}

The use of automated hematology analyzers to examine complete blood count (CBC) is very common. The $C B C$ is applied to diagnose anemia, to identify acute and chronic illness, bleeding tendencies and white blood cell disorders by both general practitioners and other medical specialties. There are a number of pre-analytical and analytical factors that cause false $C B C$ results. Red blood cell (RBC) counts, hemoglobin $(\mathrm{Hb})$, mean cell volume (MCV), white blood cell (WBC) count and platelet (PLT) count are parameters measured by hematology analyzers that are affected by spurious values in several situations. These situations commonly include the agglutination in the pres- ence of ethylenediamine tetra-acetic acid (EDTA), insufficiently lysed RBC, erythroblast, platelet aggregates, cryoglobulins, agglutinins, lipids, hemolysis, and elevated WBC counts (1).

In the present case, we evaluated cold agglutinins as a reason for the mismatch between hematocrit and hemoglobin values. There are several case studies associated with cold agglutinins; however, these studies have been generally presented in a clinical perspective. Laboratory findings were also not sufficiently available in these studies. Only few cases have recently drawn attention to the importance of pre-analytical affect of cold agglutinins on $\mathrm{CBC}$ results $(2,3)$. To our knowledge, the present 
study is also a unique case report of spurious CBC results associated with cold agglutinins using the ABX Pentra 80 (Horiba Medical, Montpellier, France) hematology analyzer.

\section{Materials and methods}

\section{Case history}

An anticoagulated blood sample $\left(\mathrm{K}_{3}\right.$ EDTA, $2 \mathrm{~mL}$, Golden Vac-Tube, GongDong Medical Technology Co., Zhejiang, China) drawn from a 70-year old female patient was analyzed during routine laboratory examination. Patient had WBC $7.1 \times 10^{9} / \mathrm{L}$ and PLT count $327 \times 10^{9} / \mathrm{L}$; however, hemoglobin $(\mathrm{Hb}$ : $105 \mathrm{~g} / \mathrm{L})$ and hematocrit (HCT: $0.214 \mathrm{~L} / \mathrm{L})$ results were discordant [if $\mathrm{Hb}$ value $(\mathrm{mg} / \mathrm{dL})$ is multiplied by three, it gives $\pm 3 \mathrm{HCT}$ value (\%)], as shown in Table 1 (Sample 1). Blood samples have been transferred from patient's home to our laboratory after routine examination by a family physician. Patient had a history of cerebrovascular diseases and rheumatoid arthritis.

We first suspected hemolysis. When the tube with $\mathrm{K}_{3}$ EDTA was centrifuged at $500 \times g$ for 3 minutes, slight hemolysis appeared. Thus, to rule out problems with blood sample drawing, the physician and phlebotomist were informed to redraw the tube with $\mathrm{K}_{3}$ EDTA. One tube with $\mathrm{K}_{3}$ EDTA was drawn by home health services in non-fasting state and a $\mathrm{CBC}$ was run, but the results were not corrected; in fact, the mismatch became even more distinct $(\mathrm{Hb}$ : $104 \mathrm{~g} / \mathrm{L}$ and HCT: $0.08 \mathrm{~L} / \mathrm{L}$ ) (Sample 2 in Table 1). Moreover, the sample had not hemolysis or lipemia. We then suspected cold agglutinin. In this sample, the titer of cold agglutinin was determined and a peripheral blood smear was also prepared.

\section{The determination of cold agglutinin titer}

The titer of cold agglutinin was determined according to a previously described method (4). Ten tubes were prepared to determine the titration of cold agglutinins. $1.5 \mathrm{~mL}$ of physiologic saline was placed in tube 1 and $1.0 \mathrm{~mL}$ of physiologic saline in tubes $2-10.0 .5 \mathrm{~mL}$ of patient's serum was added to tube 1, mixed and $1 \mathrm{~mL}$ of the mix was transferred to tube 2 , from which $1.0 \mathrm{~mL}$ was then transferred to tube 3; the process was reiterated until tube 9 (tube 10 served as a cell control). By this method, dilutions from 1:4 to 1:1024 were obtained. $0.1 \mathrm{~mL}$ of patient's own erythrocyte suspension (2-5\%) was added to each tube, and the contents were mixed by vigorously shaking and then placed in racks at $4{ }^{\circ} \mathrm{C}$ overnight. Tubes were removed from the refrigerator and read immediately. Readings were made by shaking the tube 3-5 times, firmly enough to make a silk-like suspension in negative tests. The agglutination degree was recorded as $1+$ to $5+, 1+$ representing just visible agglutination and $5+$, a solid clump of cells. After reading, tubes were placed at $37^{\circ} \mathrm{C}$ for 2 hours and re-visualized.

\section{Results}

The titration of the cold agglutinin was found to be $4+$ at 1:4 dilution ratio and $1+$ at 1:64 dilution ratios. After incubation at $37^{\circ} \mathrm{C}$ for 2 hours, reversibility of agglutination was observed. Thus, agglutination was confirmed as cold agglutinin.

As shown in Figure 1A, when the blood smear was examined under the microscope, clusters of erythrocytes were observed in each field.

After obtaining these findings, an expert phlebotomist and specialist of medical biochemistry visited the patient to draw blood at her home. The drawn specimen in non-fasting state was immediately transferred to the laboratory. During transfer, the specimen had not been exposed to the cold. The flat plastic container $(500 \mathrm{~mL})$ had been filled with water warmed to approximately $40{ }^{\circ} \mathrm{C}$. The specimen had been placed in this hot plastic container and transferred inside the Styrofoam box. The $\mathrm{K}_{3}$ EDTA tube was immediately run on the hematology analyzer. It seemed that all the CBC results were valid (Sample 3 in Table 1). Clusters of erythrocyte were not observed in the blood smear prepared from this sample (Figure 1B). Subsequently, this specimen was placed at $4{ }^{\circ} \mathrm{C}$ for $30 \mathrm{~min}$, and re-analyzed. Although leukocyte and platelet values were not changed, a mismatch between HCT and $\mathrm{Hb}$ was again observed (Sample 3a in Table 1). The specimen was then stored at room temperature for 1-hour and re-analyzed, but the results remained the same (Sample 3b in Table 1). 
TABLE 1. The results of $C B C$ analysis in different samples.

\begin{tabular}{cccccc}
\hline & Sample 1 & Sample 2 & Sample 3 & Sample 3a & Sample 3b \\
\hline $\mathrm{RBC}\left(\times 10^{12} / \mathrm{L}\right)$ & 1.86 & 0.65 & 3.26 & 0.45 & 0.46 \\
$\mathrm{Hb}(\mathrm{g} / \mathrm{L})$ & 105 & 104 & 100 & 109 & 105 \\
$\mathrm{HCT}(\mathrm{L} / \mathrm{L})$ & 0.214 & 0.080 & 0.298 & 0.058 & 0.061 \\
$\mathrm{MCV}(\mathrm{fL})$ & 115 & 123 & 91 & 127 & 133 \\
$\mathrm{MCH}(\mathrm{pg})$ & 56.4 & 159.8 & 30.8 & 239.9 & 229 \\
$\mathrm{MCHC}(\mathrm{g} / \mathrm{L})$ & 491 & 1295 & 337 & 1884 & 1724 \\
$\mathrm{PLT}\left(\times 10^{9} / \mathrm{L}\right)$ & 327 & 364 & 324 & 325 & 328 \\
WBC (x 109/L) & 7.1 & 6.9 & 7.7 & 7 & 6.8 \\
\hline
\end{tabular}

Sample 1: First sample with slight hemolysis; Sample 2: The sample transferred using the routine method without hemolysis or lipemia; Sample 3: The sample transferred without exposition to cold and analysed immediately; Sample 3a: Sample 3 analysed after placing the sample at $4^{\circ} \mathrm{C}$ for $30 \mathrm{~min}$; Sample 3b: Sample 3 analysed after placing the sample at room temperature for 1 hour.

$\mathrm{RBC}$ - red blood cells; $\mathrm{Hb}$ - hemoglobin; $\mathrm{HCT}$ - hematocrit; $\mathrm{MCV}$ - mean corpuscular volume; $\mathrm{MCH}$ - mean corpuscular hemoglobin; MCHC - mean corpuscular hemoglobin concentration; PLT - platelets; WBC - white blood cells.
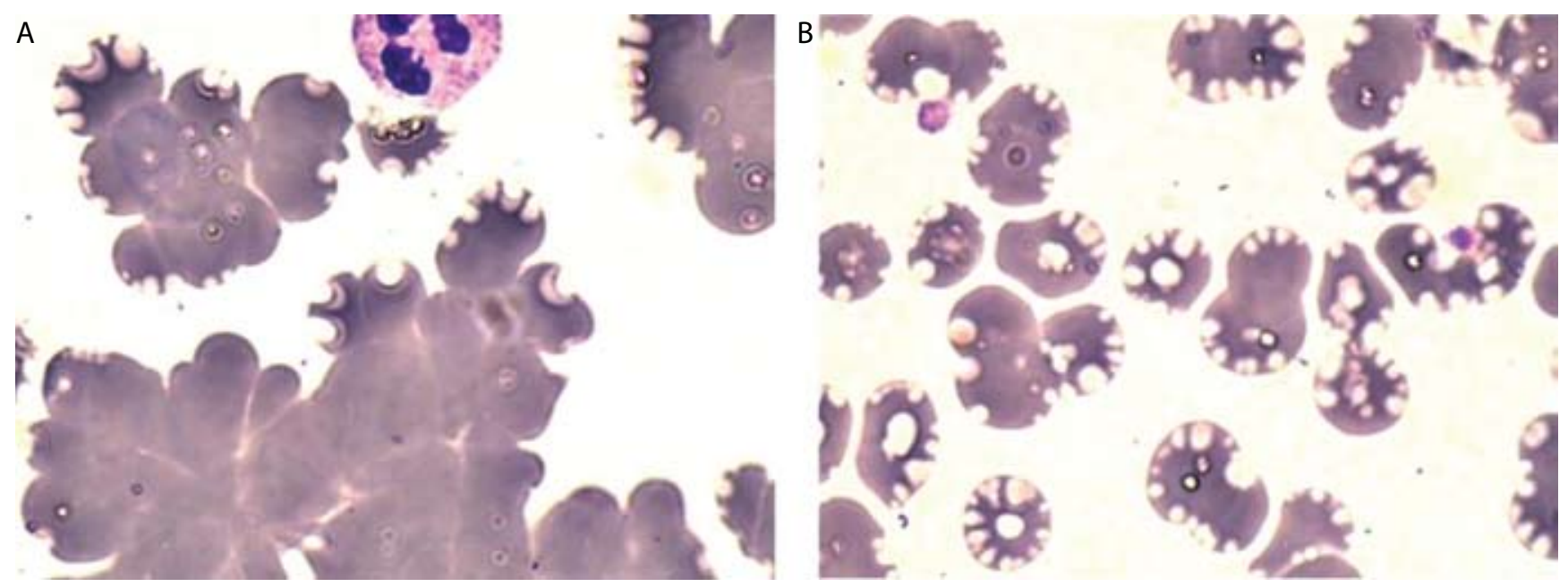

Figure 1. Peripheral blood smear, May-Grunwald-Giemsa stain, 1000x. A: Redrawn first sample with clusters of erythrocyte, B: Sample transferred without exposition to cold.

\section{Discussion}

Cold agglutinins are antibodies that are usually specific for I antigen, an erythrocyte surface carbohydrate macromolecule. Cold agglutinins bind to the erythrocyte surface antigen at a temperature optimum of $0-4{ }^{\circ} \mathrm{C}$, which causes agglutination of erythrocytes and, thereby, impaired microcirculation ranging from moderate acrocyanosis to severe Raynaud's phenomenon (5). The antigenantibody complex also induces the classical com- plement pathway, resulting in extravascular hemolysis. The physiologic cooling of blood in peripheral vessels is usually sufficient to cause hemolysis and circulatory symptoms in patients with high thermal amplitude of cold agglutinins (6). The clinical effects of cold agglutinins are dependent on both the titer and the thermal amplitude of antibody (7). 
Cold agglutinins are rare and only low titers can be found in the serum of healthy individuals. Cold agglutinins may be monoclonal or polyclonal. Monoclonal antibodies are usually found in patients with idiopathic forms of cold agglutinin disease or lymphoproliferative disorders. Polyclonal antibodies usually appear after infection, most often with Mycoplasma pneumonia, Ebstein-Barr virus or cytomegalovirus (7).

Cold agglutinins can cause hemolysis in patients undergoing cardiac surgery during a hypothermic cardiopulmonary bypass. Screening for cold agglutinin in all patients is not recommended; however, it can be useful in specific patient groups (8).

In the presence of cold agglutinins, we found decreased HCT and elevated MCV values. Hemoglobin concentration was unaffected by cold agglutinins, thereby, calculated $\mathrm{MCH}$ and $\mathrm{MCHC}$ values were prominently elevated. Leukocyte and platelet counts were also found to be unaffected by cold agglutinins. In the present case, the analysis of $C B C$ was performed on ABX Pentra 80 hematology analyzer. RBC is measured by an electronic impedance variation principle on ABX Pentra 80. MCV and HCT are calculated directly from the RBC histogram. The impedance method of counting and sizing cells is based on measurable changes in electrical resistance produced by non-conductive cells suspended in conductive isotonic electrolyte solution. This electrical resistance is manifested as a pulse that has a height directly proportional to the cell size. Red blood cells, platelets and leukocytes are counted and sized according to the total number and heights of produced pulses (9). Cells between 30 to $300 \mathrm{fL}$ are considered and counted as red blood cells on Horiba ABX Pentra. The microaggregates of erythrocyte are counted as single cells and large clumps of cells are excluded from the count, which lead to decreased RBC count (9). These abnormal RBC values will lead to abnormal MCV and HCT results.

We met with the present case in winter. Therefore, the cold agglutinin forming might be the result of the fact that blood samples were exposed to cold weather during transfer from patient's home to our laboratory. When the patient's previous results were reviewed, $C B C$ results were found to be valid. This is most likely due to drawing the blood samples at the hospital, without exposure to cold. In addition, we found that $\mathrm{CBC}$ results were valid if the blood drawn from the patient was immediately transferred to the laboratory without being exposed to cold.

The interference of cold agglutinin on RBC and $\mathrm{HCT}$ results has previously been reported using an older automated hematology analyzer $(10,11)$. It is seems that cold agglutinins can still cause artifactual changes on RBC and related parameters. This might be due to the counting of RBC by the impedance method, which is widespread among hematology analyzers produced different manufactures. In accordance with our case report, Kakkar (2) revealed spurious $C B C$ results due to cold agglutinins on Advia 60 (Bayer diagnostics) hematology analyzer. In his report of two cases, he reported HCT to be spuriously low and discordant with $\mathrm{Hb}$. MCV, MCH and MCHC values have also been found to be elevated.

Similarly, Breuer et al. (3) reported four patients with cold agglutinins whose RBC parameters described were incompatible and spurious. They showed that cold agglutinins caused artificially decreased red blood cell counts and increased MCV and $\mathrm{MCHC}$ in the automated Coulter STKS hematology analyzer. It was also noted that leukocyte and platelet counts remained unchanged. In a more recent case, Reddy et al. (12) reported elevated MCHC and MCV in a 12-year-old girl with mixed autoimmune hemolytic anemia.

The in vitro phenomenon of cold agglutination results in a spurious increase in MCV and MCHC and a decrease in the RBC count given by automated hematology analyzer; however, different findings have been reported in some clinical case reports.

In a 55-year old woman with a history of rheumatoid arthritis, Bizzaro et al. (13) presented in vitro platelet clumping due to EDTA-dependent autoantibodies and RBC agglutination due to cold agglutinins. Although they observed elevated MCHC in laboratory examination, the MCV value was reported as normal. In another study, Lee et al. (14) identified cold agglutinin in a case of 75-year old 
woman patient with non-Hodgkin's lymphoma. They identified RBC agglutination related to cold agglutinins; however, a normal MCHC value was reported. Laboratory methodology and findings were, unfortunately, not obtained from these studies. Therefore, a satisfactory comparison could not be done.

In conclusion, cold agglutinins interfere with the analysis of RBC and RBC-related parameters (HCT, MCV, MCH and MCHC); however, $\mathrm{Hb}, \mathrm{WBC}$ and PLT counts are not affected. In addition, the presence of cold agglutinins is easily displayed by the cold agglutinin titer test. It is also visible in a blood smear. Also, the effect of cold agglutinin on CBC

\section{References}

1. Zandecki M, Genevieve F, Gerard J, Godon A. Spurious counts and spurious results on haematology analysers: a review. Part II: white blood cells, red blood cells, haemoglobin, red cell indices and reticulocytes. Int Jnl Lab Hem 2007;29:21-41.

2. Kakkar N. Spurious automated red cell parameters due to cold agglutinins: a report of two cases. Indian J Pathol Microbiol 2004;47:250-2.

3. Breuer GS, Raveh D, Rudensky B, Rosenberg R, Ruchlemer $R$, Halevy J. Remember the blood smear: A clinical laboratory vignette. IMAJ 2002;4:1089-90.

4. Bryant NJ, eds. Laborotory Immunology and Serology. 2nd ed. London: W.B. Saunders, 1992.

5. Berentsen S, Beiske K, Tiønnfjord GE. Primary chronic cold agglutinin disease: An update on pathogenesis, clinical features and therapy. Hematology 2007;12:361-70. http:// dx.doi.org/10.1080/10245330701445392.

6. Berentsen S. How I manage cold agglutinin disease. $\mathrm{Br} \mathrm{J} \mathrm{Ha}-$ ematol 2011;153:309-17. http://dx.doi.org/10.1111/j.13652141.2011.08643.x.

7. Berentsen S, Beiske K, Tiønnfjord GE. Diagnosis and treatment of cold agglutinin mediated autoimmune hemolytic anemia. Blood Rev 2012;26:107-15. http://dx.doi. org/10.1016/j.blre.2012.01.002. results may be prevented if the blood drawn from the patient is immediately transferred to the laboratory without exposure to cold. Lastly, clinicians should be aware of the fact that anemia diagnosis based on low HCT alone may be misleading.

\section{Acknowledgements}

We thank Ercan Güneş, Adem Taka, and Pervin Köksal for their technical assistance. We thank Deniz Inci for helping to take the images of blood smears.

\section{Potential conflict of interest}

None declared.
8. Hubeek I, ter Heide H, van Solinge WW, de Vooght KMK. Hypothermic cardiopulmonary bypass surgery in a 7-year-old boy with a cold agglutinin. Ann Hematol 2012;91:1989-90. http://dx.doi.org/10.1007/s00277-012-1515-1.

9. Constantino BT. The red cell histogram and the dimorphic red cell population. Lab Med 2011;5:300-8. http://dx.doi. org/10.1309/LMF1UY85HEKBMIWO.

10. Lawrence C, Zozicky O. Spurious red cell values with the Coulter counter. N Engl J Med 1983;309:925-6. http://dx.doi. org/10.1056/NEJM198310133091517.

11. Solanki DL, Blackburn BC. Spurious red blood cell parameters due to serum cold agglutinins: observations on Ortho ELT-8 Cell counter. Am J Clin Pathol 1985;83:218-22.

12. Reddy VRS, Samayam P, Ravichander B, Bai U. Autoimmune hemolytic anemia: mixed type-A case report. Indian J Hematol Blood Transfus 2011;27:107-10. http://dx.doi. org/10.1007/s12288-011-0065-3.

13. Bizzaro N, Fiorin F. Coexistence of erythrocyte agglutination and EDTA dependent platelet clumping in a patient with thymoma and plasmocytoma. Arch Pathol Lab Med 1999;123:159-62.

14. Lee EJ, Kueck B. Rituxan in the treatment of cold agglutinin disease. Blood 1998;92:3490-91. 